\title{
Health Professionals' Perspectives on E-Health and Social Media in Thailand
}

\author{
Suttisak Jantavongso \\ College of Information and Communication Technology, Rangsit University, Pathumtani, Thailand
}

Received date: 25 February 2015; Accepted date: 15 June 2015; Published date: 11 February 2016

Copyright (C) 2016. Suttisak Jantavongso. Distributed under Creative Commons CC-BY 4.0

\begin{abstract}
The core of this study evolved on perspectives of health professionals in Thailand on electronic health (e-health) and social media. Two main objectives were included as follows: (A) to provide a descriptive status of e-health and social media; and (B) to identify inhibitors and drivers for social media engagement. The study was a non-experimental and a quantitative research adopting a survey approach. The data were collected during April to June 2014 through the in-depth interviews. Health professionals within Bangkok and the Metropolitan areas, and other provinces in Central Thailand were the target population. Thirty-five Thai health professionals were randomly selected using a random sampling method with replacement. This clearly met the necessary conditions of the "Central Limit Theorem" aka CLT. The findings revealed that health professionals in Thailand have used social media within their work contexts. Social media were used to connect between Thai health professionals and patients. The factor of "familiarity" was the main reason behind the selections of social media platforms by the health professionals. The top three devices used by the health professionals to access to social media were personal computers, smartphones, and notebooks. Following this, Facebook, LINE, and Google+ were the three major social media platforms. The top three ranked benefits of social media were "receive other helpful news and interests", "receive information of the organization", and "communicate with various departments within the organization". On the other hand, Thai health professionals believed "ethical problems in using social media", "contents of negative criticisms on the organization", and "lack of content management" were the social media inhibitors.
\end{abstract}

Keywords: social media, e-health, health professionals

\section{Introduction}

The economic development and performance of a country vitally depends on the wellbeing and health of its people. Similarly, the wellbeing and health of Thais determines a quality of life that its members enjoy, and in turn, their ability to

be productive participants in their communities and the workforce
(Jantavongso, 2013a). In this regard, a high quality healthcare system is a foundation of Thai social and economic wealth. Therefore, maintaining equal access to safe and effective healthcare should always be a key priority of the Thai government. Moreover, Thailand has been moving towards the quality healthcare system since 1975. An example of these initiatives is a free and universal access to the healthcare system targeted at the low incomes since 2001 (Prakongsai et al.,

Cite this Article as: Suttisak Jantavongso (2016), "Health Professionals' Perspectives on E-Health and Social Media in Thailand", Journal of e-health Management, Vol. 2016 (2016), Article ID 510007, DOI: $10.5171 / 2016.510007$ 
2009). This has resulted in a significant impact on Thais in the direct household spending on healthcare; and promoted an equitable quality healthcare system.

Electronic healthcare or e-healthcare or simply e-health plays a significant role in quality improvement, equity, and cost reduction in a healthcare system in Thailand (Kijsanayotin et al., 2010). The study by Kijsanayotin et al. (2010) reported that there were a mixture of paper based and computerized patient information being used in the healthcare systems in Thailand. Nearly 1,001 hospitals in the Thai public sector and 10,068 Primary Care Units (PCUs) have already implemented some degrees of Electronic Medical Records (EMRs) and Electronic Health Records (EHRs) capabilities (Kijsanayotin et al., 2010). These records or information can be categorized into administrative and clinical data. Administrative data are patient information used for reimbursement, administration and reports, while clinical data are for patient care such as laboratory data, pharmacy data, and providers' notes. The point to be noted here is that, this information is already being transmitted electronically.

This implies that e-health covers the communications between patients, health professionals, and health providers, through Information and Communication Technologies or ICTs (Kelly, 2011). Examples of these technologies are EMRs, EHRs, telemedicine services, as well as social media services. Despite this, the wider adoption of e-health in Thailand raises new ethical and regulatory concerns. E-health involves the processing of patient health information. E-health providers and especially health professionals need to ensure that the patient health information remains private and secure.

Likewise, a rapid increase in the number of users as well as an advancement in technologies of social media over the past few years have been observed. Thus, social media embrace technologies such as new media, digitalizing, and social media networking (Eid and Ward, 2009). "Internet Medicine" is another term for ehealth referring to health services and information delivered through the Internet (Jacobs, 2011). Social media provides a cost effective method for patients to receive information and social support on their illness. Whereas, EHRs are made to support mainly a one-to-one communication between a patient, health professional and provider; e-health via social media provides many-to-many, many-to-one, and one-to-many communications. This is essentially extending the patients' participation in their own decisions and health management, at the same time providing tools for medication assistance and research on treatment (Jacobs, 2011).

As with other new technologies, the emergence between e-health and social media used by health professionals gives rise to ethical questions. Ethical issues have been given a new urgency. There are growing concerns about health professionals and healthcare providers' use and access to Personally Identifiable Information (PII) of the patients. Patients are increasingly worried about their privacy on social media (Jantavongso, 2013b).

\section{Research Objectives}

This paper is built upon the author's previous research. Two studies in particular are of note. These are "Ethics and E-Health in Thailand" (Jantavongso, 2013a), and "Ethics and Social Media" (Jantavongso, 2013b). Two main research objectives provide three foci of the research presented in this paper. The first (A) objective is to provide a descriptive status of health professionals' use of ehealth and social media in Thailand. The second (B) is to identify issues that were considered by the health professionals to be important and the perceived barriers to the use of social media for work in Thailand. The third (C) is to report a finding on factors which drive Thai health professionals in Thailand from engaging in social media.

\section{Literature Review}

\section{E-health in Thailand}

Thailand has had a successful and long history of healthcare development. Thailand has continually achieved 
remarkable progress in healthcare reforms (Sirilak, 2007). Thus, nearly all of the Thais are covered through a comprehensive healthcare (Chowdhury and Phaholyothin, 2012). Thai's healthcare system is structured and provided by both public and private sectors. The study by the Ministry of Public Health (2012) reports that there are 13,036 units of public health services in Thailand. Of these figures, 1,027 are public, while 321 are private hospitals. In addition, private clinics also play an important role as primary healthcare providers. There are approximately 16,800 private clinics throughout Thailand (Pagaiya and Noree, 2009). As mentioned earlier, 1,001 public hospitals and 10,068 PCUs have already implemented some levels of EMRs and EHRs capabilities (Kijsanayotin et al., 2010).

Thai hospitals had successfully implemented e-health systems since 2009 (Kok, 2009). Many Thai hospitals had digitized their hospital work processes. The e-health system is able to increase the number of patients a hospital can handle each day, in turn improving safety and reducing its patients' invoices. Invoice payments, Human Resources (HRs), record keeping and stock can be done electronically, allowing the health professionals to concentrate on their duties. In particular, an electronic prescription (e-prescription) system allows the hospital to eliminate errors from illegible handwriting. Moreover, Thailand is one of the leading nations among developing countries, that the use of ICT applications including e-health services is pervasive. Thailand has achieved an elevated level of access to e-health services with the use of ICT and ICT expertise (Kijsanayotin et al., 2010). Three levels of e-health in Thailand are identified by Kijsanayotin et al. (2010). The first level (A) is the foundation policies and strategies which include the creation of an appropriate governing body involving a multi-stakeholder at the national level. The second level (B) is e-health development models. This is followed by the final level (C), e-health applications.

\section{Social Media in Thailand}

Social media can be defined as "Social interaction through the use of applications on available tools, many of which are the Internet based" (Jantavongso, 2013b). These applications include applications such as Facebook, Twitter, LINE, LinkedIn, Google+, Blogs, WhatsApp, Tango, WeChat, Instagram, YouTube, and SKOUT. Social media in this study can form relationships and create social networks. Therefore, social media have not only changed the approach patients and health professionals communicate, but also the ways they have socialized. Social media have become an essential element of many healthcare providers in Thailand.

"SixDegrees.com" was launched in 1997 as the first recognizable social media site (Boyd and Ellison, 2007). "SixDegrees.com" allowed users to create their profiles and list their friends. "SixDegrees.com" had promoted itself as a tool to assist people connect with and send messages to others. Although SixDegrees.com had attracted the number of users in millions, it was not a sustainable business. The site closed in 2000. Despite this, the origin of social media in Thailand was dated back to 1995 when the Internet became commercialized (Kagami et al., 2004, Kerdpoka and Kataya, 2012). "Talk on Unix", "Pirch", "ICQ", "QQ", and "MSN or Windows Live Messenger" were once five of the most popular social media applications in Thailand (Iadthong, 2013).

Thailand is ranked $5^{\text {th }}$ in terms of the time spent on social media each day in 2015 (Kemp, 2015). 32 million of 64.9 million have active social media accounts. Facebook is the top active social platform. 30 million are Facebook users, followed by 26.2 YouTube users, and Twitter and Instagram at 4.5 and 1.7 million respectively in Thailand. Out of the 30 million Facebook users, 28 million users are actively on mobile devices. Additionally, a single YouTube user visits approximately 16.6 times per month spending about 17.3 minutes per visit. 3.4 of 4.5 million Twitter users tweet in Thai (Vichienwanitchkul, 2015). Moreover, there are 24 million LINE users in Thailand with the current growth rate of $+20 \%$. Thailand is ranked $2^{\text {nd }}$ place in the world with most LINE users after Japan (Zocial Inc., 2014). 


\section{Social Media Used by Thai Health Professionals}

A study by Jacobs (2011) identifies social media in healthcare services as the possibility of finding others in similar needs and sharing information about symptoms, treatments, and conditions. Social media would assist patients and health professionals in making healthcare decisions through experiences and shared collective learning. "PatientsLikeMe", "CureTogether", and "MedHelp" websites provide these services allowing the patients to monitor their symptoms and medication routines over period. The four primary social media related health services are: (A) emotional support and information sharing, (B) questions and answers with physicians, (C) quantified self-tracking, and (D) clinical trial access. For example, "PatiensLikeMe" provides medical conditions and services for emotional support and information sharing, quantified self-tracking, as well as clinical trial access (Jacobs, 2011).

Unlike Jacobs (2011), social media for health professionals in Thailand are slightly different. The use of social media for Thai health professionals is emphasized on Facebook and LINE applications. For example, the Deputy Minister of Public Health in 2013 encouraged the patients who live in the North Region of Thailand to consult their doctors using LINE application. Advices via LINE messages are believed to be quick, accurate, pointing a patient the right direction, and in a timely manner (Thairathonline, 2013). LINE, Facebook, Twitter, and WhatsApp are the four main social media applications that allow patients to seek a second opinion. Image scans and reports from a hospital can be quickly uploaded and viewed by remote specialists. Specialists' opinions can be discussed online in real time (Lokapattana, 2014), see Figure 1 for an illustration.

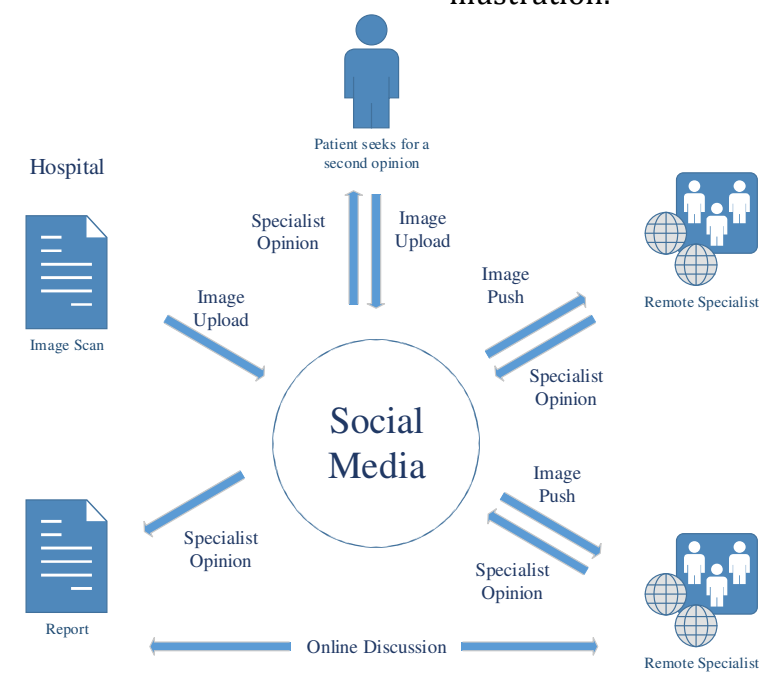

Figure 1: Usage of Social Media by Thai Health Professionals and Patients

Thai health professionals already use social media to network with others and patients. The social media applications or platforms are selected based on their "familiarity" of the applications by the health professionals. One of the reasons behind the popular use of social media is the nonpayment (free cost) for applications from the healthcare providers. Other advantages include: (A) the high number of existed users, (B) able to send a picture, (C) notification, (D) easy to use, and (E) able to discuss in groups. While there is a number of benefits of social network in a Thai healthcare system, discussing the details of patients should be done with their consents. Discussing a case in real-time in a public space, Thai health professionals have to consider whether the patient will be able to identify themselves even if no one else are able to. Without their explicit consents, this in itself may reduce trust in 
the health professionals (Lokapattana, 2014).

\section{Defining Thai Health Professionals}

Thai health professionals in the broadest sense can be categorized into private and public healthcare providers. Three major categories of Thai health professionals are: (A) health management and support personnel, (B) health professionals, and (C) health associate professionals. Health management is, for example, health service managers, and other general management, while health support personnel comprise of ambulance drivers, building maintenance staff, administrative, support staff, et cetera. (Statistical Forecasting Bureau, 2013; Bureau of Policies and Strategy, 2013). Health professionals are, for example, medical doctors, nursing professionals, and midwifery professionals. Health associate professionals include medical imaging and therapeutic equipment technicians, medical and pathology laboratory technicians, pharmaceutical technicians and assistants, medical and dental prosthetic technicians, medical records and health information technicians, et cetera. Moreover, the classification of Thai health professionals in this study maps occupation categories by the World Health Organization or WHO (2010): (A) health professionals, (B) health associate professionals, (C) personal care professionals in health services, (D) health management and support personnel, and (E) other health service providers not elsewhere classified.

In addition to these, there were approximately $137,600 \quad$ health professionals in the private sector. Of these, 77,397 were health professionals, 33,712 were health associate professionals, 26,491 were health management and support personnel (Bureau of Policies and Strategy, 2013). In terms of the number of health professionals in the public sector, there were around 178,543 (Bureau of Policies and Strategy, 2013). Of these 178,543 health professionals, 115,598 were health professionals, 14,276 were health associate professionals, 48,669 were health management and support personnel respectively.

\section{Research Methodology}

This section outlines the research methodology applied in this study.

\section{Research Approach}

This study is a quantitative research using a survey approach. It also can be classified as a non-experimental research. While there are survey methods to collect data, the interview technique is selected amongst all others to collect data. The first reason was by using an interview approach that allows the interviewer to collect feedback during the question time, additional information can be given when a response seems inappropriate or incomplete. The second reason was that the response rates of interviews are higher when compared with other survey methods. Moreover, a survey approach is the most frequently used empirical research method in Information Technology (IT) research (Shanks et al., 1993).

\section{Sample Framework}

The sampling frame used in this study was developed based on a member list of the "Software workshop training for health professionals for Thai healthcare industry in 2014 in association with Thai Medical Informatics Association (TMI), Software Industry Promotion Agency (Public Organization) or SIPA, and Rangsit University". The list provides the names of Thai health professionals, their addresses, telephone numbers, persons to contact, and their products information.

\section{Sample Method}

A random sampling method was applied. Participants in this study were selected by a simple random sample method using a random numbers table (Deakin et al., 2002). From an analysis perspective, the selection methods were random in nature and contain no identifiable source of systematic bias.

\section{Sampling Size}

"Central Limit Theorem" or CLT is of vital importance for statistical inference in this study. The CLT states that the samples 
should be of "equal size", "sufficiently large", and "with replacement". Following Deakin et al. (2002), the general rule of thumb for "sufficiently large" is that the number of observations should be "equal to" or "greater than" 30 . In this study, 35 participants were interviewed thus clearly addressing the criteria for a "sufficiently large" sample. In the case of sampling with replacement, the key is the requirement of equally likely outcomes in each drawing, namely that the process of selection is unbiased and this is closely approximated in the random selection process that was used. As such, an appeal to the Central Limit Theorem appears reasonable.

Given this, an explicit assumption is made that the results of the analysis are expected to be normally distributed. Moreover, the process is expected to mirror the requirement for equally likely selection given that the random nature of the selection process.

\section{Data Collection}

Thirty-five Thai health professionals were selected using the random sampling method described previously. Prospective participants were then contacted by emails, LINE chat messages, Facebook messages, letters, facsimiles, or telephone calls to arrange appointments for an interview at a suitable time. The interviews were conducted between April and June 2014.

Prior to the interviews, the questions used in the interviews were first developed in English. However, since English is not the official language in Thailand, some participants may not completely understand the questions. The questions were translated into Thai to avoid miscommunication and misinterpretation.

The interview instrument was evaluated by three experts using the Index of Item Objective Congruence (IOC) to rate individual items on the degree to which they "do" or "do not" measure specific objectives. Each expert evaluates each item by giving the item a rating of " 1 " for clearly measuring, "- 1 " for clearly not measuring, or " 0 " for degree to which it measures the content area is unclear for each objective (Turner et al., 2002). Items rated below 0.5 were excluded.

\section{Data Analysis}

Descriptive statistics was used to analyze data in this study because they describe the state of affairs as it exists. The descriptive statistics include measurement, classification, analysis, comparison, and interpretation of data (Mutua et al., 2013).

\section{Research Results}

This section presents the detail findings of the participating Thai health professionals.

\section{General Characteristics of the Sample}

Thirty-five health professionals participated in this survey. In the sample of these health professionals, 20 were female and 15 were male. The ratio between all the health professionals was 57:43. The majority of participants were aged between 31 and 40 at 42.86 percent. This was followed by the 21-30 years old group at 40 percent, the 41-50 years old group at 14.29 percent, and the 51 years old and above at 2.85 percent respectively. 54.30 percent of the participants held bachelor's degrees, while 45.70 percent of the participants had master's degrees.

In terms of the work location of the participants, 80 percent of the participants were located in Bangkok and the Metropolitan areas, while the rest, 20 percent of the participants worked in the Central region in Thailand. The majority of the participants, 77.14 percent were health associate professionals, followed by health professionals at 17.14 percent, and health management and support personnel at 5.72 percent respectively.

\section{Usage of E-Health by Thai Health Professionals}

E-health lies at the heart of a high quality healthcare system which in turn leads to a foundation of Thailand's social and economic wealth, and equal access to safe and effective healthcare. of the participants, 34.29 percent had used ehealth. 45.71 percent of the participants did not use e-health previously, while 20 
percent of the participants were not sure whether they had used e-health at work or not.

Of those participants who use e-health on a daily basis, 33.30 percent had used e- health for more than 10 years, followed by 25 percent between 2 and 5 years, 16.70 percent between 5 and 10 years and less than 1 year, and 8.30 percent between 1 to 2 years respectively.

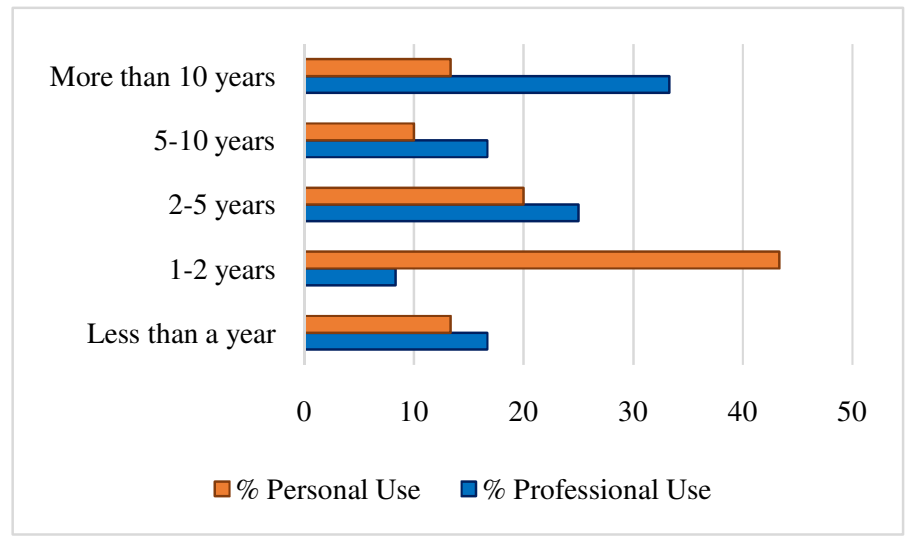

Figure 2: Personal versus Professional Usage of Social Media by Health Professionals

\section{Usage of Social Media by Thai Health Professionals}

Almost 88 percent of the participants used social media for their work. The majority of the participants, 43.34 percent used social media between 1 to 2 years, followed by 2 to 5 years at 20 percent. Equally at 13.33 percent were less than a year and more than 10 years. The least 10 percent were between 5 and 10 years.
In contrast to the above result, all of the participants used social media in their daily lives. Of these, 33.33 percent used social media between 5 and 10 years, followed by 2 to 5 years at 27.27 percent, 1 to 2 years at 21.21 percent, more than 10 years 15.15 percent, and less than a year 3.03 percent. Figure 2 demonstrates the comparison of personal usage versus professional usage of social media by Thai health professionals, see Figure 2.

\section{Table 1: Numbers and percentages of the participants' devices for social media usages}

\begin{tabular}{|l|l|l|}
\hline Devices & Numbers & Percentages \% \\
\hline Personal Computers & 26 & 31.32 \\
\hline Notebooks & 18 & 21.69 \\
\hline Smartphones & 24 & 28.92 \\
\hline Tablets & 12 & 14.46 \\
\hline Other Devices & 3 & 3.61 \\
\hline
\end{tabular}

From Table 1, the majority of the participants, 31.32 percent, used social media via personal computers, followed by 28.92 percent via smartphones. 21.69

Facebook was the most used platform chosen by the participants at 30.70 percent. LINE was the second most used percent of the participants accessed social media through notebooks, 14.46 percent through tablets, and 3.61 percent through other devices.

platform at 25.44 percent, followed by Google+ at 16.67 percent, and YouTube at 13.16 percent. Slideshare and Twitter were 
equally at 3.51 percent, followed by WordPress and others at 2.63 percent each, and Wikipedia was the least used platform by the participants at 1.75 , see Table 2

\section{Table 2: Numbers and percentages of the participants' devices for social media usages}

\begin{tabular}{|l|l|l|}
\hline Social Media Platforms & Numbers & Percentages \% \\
\hline Facebook & 35 & 30.70 \\
\hline Google+ & 19 & 16.67 \\
\hline LINE & 29 & 25.44 \\
\hline Slideshare & 4 & 3.51 \\
\hline Twitter & 4 & 3.51 \\
\hline Wikipedia & 2 & 1.75 \\
\hline WordPress & 3 & 2.63 \\
\hline YouTube & 15 & 13.16 \\
\hline Other Platforms & 3 & 2.63 \\
\hline
\end{tabular}

The majority of the participants, 37.15 percent spent between 1 and 2 hours a day on social media, followed by more than 4 hours per day at 34.29 percent. 22.86 percent of participants spent between 2 to 4 hours per day, and 5.71 percent spent less than an hour per day on social media, see Figure 3.

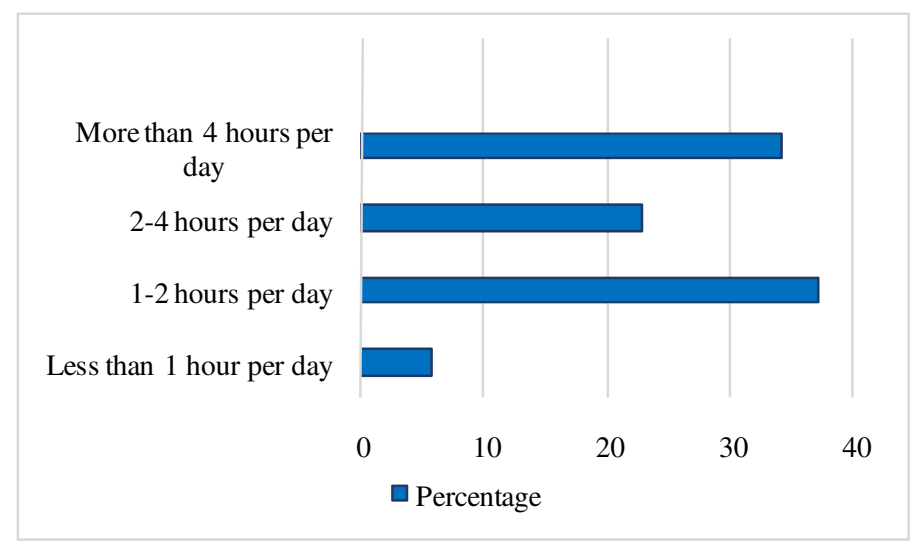

Figure 3: Time Spent on Social Media by Health Professionals in Percentage

91.43 percent of the participants used social media on a daily basis. Only 8.57 percent of the participants used social media once every 2 or 3 days. 


\section{Experience with Social Media by Thai Health Professionals}

54.29 percent of the participants used social media for work at the moderate level, while 40 percent used social media for work at the heavy level. There were only two percent of the participants who used social media for personal purposes only.

Table 3: Driving factors for social media by Thai health professionals

\begin{tabular}{|l|l|l|}
\hline Social Media Driving Factors & Numbers & $\begin{array}{l}\text { Percentages } \\
\%\end{array}$ \\
\hline Receive information of the organization. & 25 & 18.12 \\
\hline Search for information on health research. & 11 & 7.97 \\
\hline Communicate with various departments within the organization. & 20 & 14.49 \\
\hline Create a social network with patient. & 7 & 5.07 \\
\hline Coordinate with staff within the organization. & 16 & 11.59 \\
\hline Participate in a health related chat room. & 18 & 13.04 \\
\hline Provide comments. & 11 & 7.97 \\
\hline Receive other helpful news and interests. & 30 & 21.74 \\
\hline
\end{tabular}

The driving factors for the adoption of social media by Thai health professionals were obtained from the extensive interviews with the participants. 21.74 percent of the participants indicated "receive other helpful news and interests" as the main benefit of social media usage at the healthcare establishments. This was followed by "receive information of the organization" at 18.12 percent, "communicate with various departments within the organization" at 14.49 percent, and "coordinate with staff within the organization" at 11.59 percent. "Search for information on health research" and "provide comments" were equally at 7.97 percent. Lastly, 5.07 percent of the participants indicated "create a social network with patient" as the least benefit, see Table 3 .

Not surprisingly, there were also inhibitors of social media identified by Thai health professionals. 17.86 percent of the participants viewed "ethical problems in using social media", followed by "contents of negative criticisms on the organization" and "lack of content management" at 11.61 percent each. "Management of negative criticisms on the organization" was next at 9.82 percent. "Dissemination of sensitive information within the organization" and "confusion on the use of social media between private and work" were at $8.93 \%$ equally. "Lack of organizational policy on the use of social media" and "communication between work colleagues" were next in line with 7.14 percent. "Communication with the public" and "lack of skills" were at 6.25 percent. Notably, "lack of technological support in the use of social media" was rated as the least important inhibitor at 4.46 percent, see Table 4. 
Table 4: Inhibitors of social media by Thai health professionals

\begin{tabular}{|l|l|l|}
\hline Social Media Inhibitors & Numbers & Percentages \% \\
\hline Ethical problems in using social media. & 20 & 17.86 \\
\hline Contents of negative criticisms on the organization. & 13 & 11.61 \\
\hline $\begin{array}{l}\text { Dissemination of sensitive information within the organization } \\
\text { (such as top secret, secret, confidential, and protected } \\
\text { information). }\end{array}$ & 10 & 8.93 \\
\hline $\begin{array}{l}\text { Lack of organizational policy on the use of social media (such as } \\
\text { guidelines, policies, and practices). }\end{array}$ & 8 & 7.14 \\
\hline $\begin{array}{l}\text { Lack of content management on the use of social media in the } \\
\text { organization. }\end{array}$ & 13 & 11.61 \\
\hline $\begin{array}{l}\text { Management of negative criticisms on the organization. } \\
\text { Confusion on the use of social media between private and work. }\end{array}$ & 10 & 9.82 \\
\hline $\begin{array}{l}\text { Lack of technological support in the use of social media (such as } \\
\text { lack of equipment, high cost, unable to use). }\end{array}$ & 5 & 8.93 \\
\hline $\begin{array}{l}\text { Communication with the public (such as providing information, } \\
\text { answering questions, managing relationships with publics, and } \\
\text { communication error). }\end{array}$ & 7 & 4.46 \\
\hline $\begin{array}{l}\text { Lack of skills. } \\
\text { criticism, misunderstanding, and gossiping). }\end{array}$ & 7 & 6.25 \\
\hline
\end{tabular}

25.51 percent of the participants expected "ethics of health professionals in the use of social media" as the highest percentage. This was followed by "social media readiness in workplace" at $21.43 \%$. Next, "there is a social media policy at work" and "social media training courses" were equally rated at 19.39 percent. Whereas technology rated last in the expectations of social media by Thai health professionals, but not necessarily unimportant, "there is a technological support in the use of social media at work" was at 14.29 percent, see Table 5.

\section{Table 5: Expectations of social media by Thai health professionals}

\begin{tabular}{|l|l|l|}
\hline Social Media Expectations & Numbers & $\begin{array}{l}\text { Percentages } \\
\%\end{array}$ \\
\hline Ethics of health professionals in the use of social media. & 25 & 25.51 \\
\hline Social media readiness in workplace. & 21 & 21.43 \\
\hline There is a social media policy at work. & 19 & 19.39 \\
\hline There is a technological support in the use of social media at work. & 14 & 14.29 \\
\hline $\begin{array}{l}\text { Social media training courses (such as a foundation course, use of } \\
\text { equipment, and social media mapping to work). }\end{array}$ & 19 & 19.39 \\
\hline
\end{tabular}




\section{Conclusion}

The research findings revealed that social media were a significant tool for Thai health professionals in Bangkok and the Metropolitan areas, and the provinces in the Central Thailand. Social media provided substantial potential benefits for Thai health professionals. This was because social media allowed patients to be able to reach other patients, other health professionals, share information, and influence collaboration. Social media played the prominent role in the healthcare system in Thailand. The majority of Thai health professionals accessed social media through personal computers, followed by smartphones, and notebooks respectively. Facebook was the most popular used social media platform, followed by LINE, and Google+. More than fifty percent of Thai health professionals used social media for work at the moderate level, while forty percent used social media for work at the heavy level. Remarkably, only two percent used social media for personal purposes only.

The top three expectations of social media by Thai health professionals were: (A) "ethics of health professionals in the use of social media", (B) "social media readiness in workplace", and (C) "there is a social media policy at work". To encounter with the ethical issues that social media had presented, Thai health professionals and patients were required to consider the risks, and be caution of issues presented by the use of social media. Through the appropriate social media policies, healthcare providers would be able to provide guidance to health professionals and patients in Thailand on how to encounter these ethical issues. A clear policy must be available. It was important for healthcare providers to manage patients' expectations about their engagement with the healthcare provider's social media profile. The policy must not be offensive and within the legislations.

The recommendation of this study was that the Thai government should empower a regulator to oversee healthcare providers, health professionals, and patients. The legal framework must be extended to cover new laws governing how healthcare providers should operate, and how patients were to be protected. While Thai patients took advantages of social media to voice their opinions, experiences and reactions, they also expected rapid replies from healthcare providers. Healthcare providers in Thailand should have policies on professional and personal use of social media. Information should be classified, to ensure that health professionals understand what sensitive information was, how it could be used, and who was authorized to access and to share contents.

\section{References}

1. Boyd, D. \& Ellison, N. 2007. Social network sites: definition, history, and scholarship. Journal of Computer-Mediated Communication, 13(1), 210-230.

2. Bureau of Policies and Strategy 2012. Report on public health resource. Bangkok: Ministry of Public Health.

3. Bureau of Policies and Strategy 2013. Report on public health resource. Bangkok: Ministry of Public Health.

4. Chowdhury, M. \& Phaholyothin, N. 2012. Healthcare in Thailand: a story to inspire confidence: The Nation [Online]. Available: http://www.nationmultimedia.com/opinio n/Healthcare-in-Thailand-a-story-toinspire-confiden-30180854.html [Accessed 15 February 2015].

5. Deakin, M., Martin, R. L. \& White, C. 2002. Quantitative business methods, Zetland, Epsilon Publishing.

6. Eid, M. \& Ward, S. J. 2009. Ethics, new media, and social networks. Global Media Journal-Canadian Edition, 2(1), 1-4.

7. Iadthong, P. 2013. History: 5 most popular chat applications [Online]. Available:

http://alicentit.blogspot.com/2013/11/his tory-5.html [Accessed 15 February 2015].

8. Jacobs, D. J. 2011. E-health diabetes self management system. honours thesis, University of Cape Town. 
9. Jantavongso, S. Ethics and e-health in Thailand. The 2nd National Conference on Medical Informatics and the Annual Meeting of the Thai Medical Informatics Association (TMI-NCMedInfo 2013), 27-29 November 2013a Bangkok.

10. Jantavongso, S. 2013b. Ethics and social media. Rangsit Journal of Information Technology, 1(2), 42.

11. Kagami, M., Tsuji, M. \& Giovannetti, E. 2004. Information technology policy and the digital divide: Lessons for developing countries, Cheltenham, Edward Elgar Publishing.

12. Kelly, B. 2011. E-health: ethical and data privacy challenges in the EU. Clinica, April, 27-28.

13. Kemp, S. 2015. Digital, social \& mobile in 2015 [Online]. We are social. Available: http://wearesocial.sg [Accessed 15 February 2015].

14. Kerdpoka, T. \& Kataya, R. 2012. Expression in social media: opportunity or problem of Thailand? [Online]. Available: http://www.academia.edu/4044530/Socia l_media_Free_speech_Hate_speech [Accessed 15 February 2015].

15. Kijsanayotin, B., Kasitipradith, N. \& Pannarunothai, S. 2010. eHealth in Thailand: the current status. Studies in health technology and informatics, 160(1), 376-380.

16. Kok, A. 2009. Thailand: successful ehealth system lauded [Online]. Available: http://www.futuregov.asia/articles/thaila nd-successful-e-health-system-lauded [Accessed 15 February 2015].

17. Lokapattana, P. 2014. Social media: the critical risk in medical informatics, Pathumthani, Rangsit University.

18. Mutua, J., Oteyo, I. N. \& Njeru, A. W. 2013. The extent of e-commerce adoption among small and medium enterprises in Nairobi, Kenya. International Journal of Business and Social Science, 4(9), 166-122.
19. Pagaiya, N. \& Noree, T. 2009. Thailand's health workforce: a review of challenges and experiences, Washington, World Bank.

20. Prakongsai, P., Limwattananon, S. \& Tangcharoensathien, V. 2009. The equity impact of the universal coverage policy: lessons from Thailand. Advances in Health Economics and Health Services Research, 21, 57-81.

21. Shanks, G., Arnott, D. \& Rouse, A. 1993. $A$ review of approaches to research and scholarship in information systems, Department of Information Systems, Faculty of Computing and Information Technology, Monash University.

22. Sirilak, S. 2007. Health policy in Thailand 2007. Bangkok: Bureau of Policy and Strategy, Ministry of Public Health.

23. Statistical Forecasting Bureau 2013. The 2012 private hospital survey. Bangkok: National Statisical Office.

24. Thairathonline. 2013. Minister of public health advises patient who live in the high area to consult their doctors with LINE application [Online]. Available: http://www.thairath.co.th/content/37854 0 [Accessed 15 February 2015].

25. Turner, R., Mulvenon, S., Thomas, S. \& Balkin, R. Computing indices of item congruence for test development validity assessments. The SAS Users' Group International Conference, 14-17 April 2002 Orlando. 1-5.

26. Vichienwanitchkul, M. 2015. Online marketing Thailand: the state of social media [Online]. Available: http://syndacast.com/infographic-onlinemarketing-thailand-the-state-of-socialmedia/ [Accessed 15 February 2015].

27. World Health Organization. 2010. Classifying health professionals [Online]. Available:

http://www.who.int/hrh/statistics/Health _professionals_classification.pdf. 
28. Zocial Inc. 2014. LINE insight behavior of LINE users in Thailand and official account [Online]. Available: http://www.zocialinc.com/en/blog/line- behavior-2014/ [Accessed 15 February 2015]. 